\title{
Bladder extramedullary plasmacytoma and synchronous bladder urothelial transitional cell carcinoma:A case report and review of the literature
}

\author{
This article was published in the following Dove Press journal: \\ Open Access Journal of Urology \\ 15 February 2011 \\ Number of times this article has been viewed
}

\section{Karan Wadhwa \\ Raj Singh \\ Lemke Z Solomon}

Department of Urology, Queen Alexandra Hospital, Portsmouth, UK
Correspondence: Karan Wadhwa Department of Urology, Queen Alexandra Hospital, Cosham, PO6 3LY, UK Tel +447725026385

Email kwadhwa@doctors.org.uk
Abstract: A 69-year-old man presented with sudden onset of macroscopic hematuria. While an ultrasound of the bladder revealed a posterior bladder mass, subsequent flexible cystoscopy demonstrated only an area of irregular urothelium. Initial general anesthetic cytoscopy and biopsy revealed conventional G2/3 T1 TCC. Histology of a further formal resection of this irregular area revealed carcinoma-in-situ and population of atypical cells with enlarged nuclei, prominent nucleoli, and varying quantities of cytoplasm showing plasma cell features. The immunohistochemistry was consistent with a plasmacytoma. There must be a high index of suspicion when ultrasound demonstrates a mass not detected by flexible cystoscopy, and biopsies/resection are advised to exclude extramedullary plasmacytoma (EMP) as the cause. EMP of the urinary bladder is a rare entity with only 21 cases reported in the literature. In this report we describe a further case of EMP of the bladder associated with synchronous transitional cell carcinoma (TCC) of the urothelium. We also highlight the important histopathological findings and review the current literature to report the outcomes of existing approaches to management of this rare form of bladder cancer. We believe this to be the first case reported in which a patient presented concurrently with bladder EMP and urothelial TCC. EMPs are highly radiosensitive tumors and in the case of head/neck disease, survival at 10 years is in the order of $65 \%$ following radical radiotherapy. Given the paucity of reported cases of primary bladder EMP, the optimal treatment regime remains unclear. In keeping with other anatomical sites current treatment is based to the assumed benefit of radical radiotherapy and prognosis appears to be better in those with no evidence of systemic disease.

Keywords: bladder cancer, extramedullary plasmacytoma, urothelial transitional cell carcinoma

\section{Case report}

A 69-year-old male ex-smoker presented with the sudden onset of macroscopic hematuria with the passage of clots. At presentation he was hemodynamically stable with a hemoglobin level of 14.6, normal renal function and clotting, and was initially managed with continuous bladder irrigation via a 3-way 20ch urethral catheter.

Urine microscopy and culture showed no evidence of pyuria and no bacterial growth. An X-ray kidney, ureter, and bladder (KUB) showed no evidence of urolithiasis and a renal tract ultrasound demonstrated normal upper tracts and an abnormal $6 \mathrm{~mm}$ lesion on the posterior bladder wall. Flexible cystoscopy revealed only an irregular area of urothelium on the left side of the bladder. This irregular area was biopsied using cold-cut 
forceps at general anesthetic (GA) cystoscopy. Histological evaluation of the biopsy revealed a papillary and solid grade 2-3 pT1 transitional cell carcinoma (TCC) with high grade dysplasia in a separate fragment of bladder tissue.

The patient further underwent a GA cystoscopy and the bladder tumor was transurethral resected. The cystoscopic findings revealed a resection crater and surrounding inflammation which was indicative of CIS, and the area was resected widely. Further histological evaluation of this formal resection of the biopsy site and surrounding urothelium showed widespread carcinoma in situ and a population of atypical cells with enlarged nuclei, prominent nucleoli, and varying quantities of cytoplasm showing plasmacytoid features with occasional mitoses (see Figure 1). On examination via immunohistochemistry the atypical cells were determined to be positive for leukocyte common antigen (LCA), CD 45 CD 138, and epithelial membrane antigen (EMA), with CD30 positivity in some cells. The epithelial markers AE1/3 and CAM5.2 were negative indicating that there was no epithelial malignancy in this material.

The plasma cells showed Lambda light chain restriction and cytoplasmic IgG. CD3 was used to stain background T-cells. The proliferation fraction as detected by Ki-67 staining was high within the plasma cell infiltrate, suggesting that this was a high grade plasma cell tumor.

Computed tomography (CT) of brain, chest, abdomen, pelvis, and skeletal surveys revealed no metastatic spread and organ confined disease (see Figure 2). A radioisotope bone scan confirmed no evidence of metastatic bony disease. Blood tests revealed normal serum calcium, ESR, and no abnormal paraprotein, free light chains, or Bence Jones protein levels. A bone marrow biopsy confirmed no evidence of myeloma.

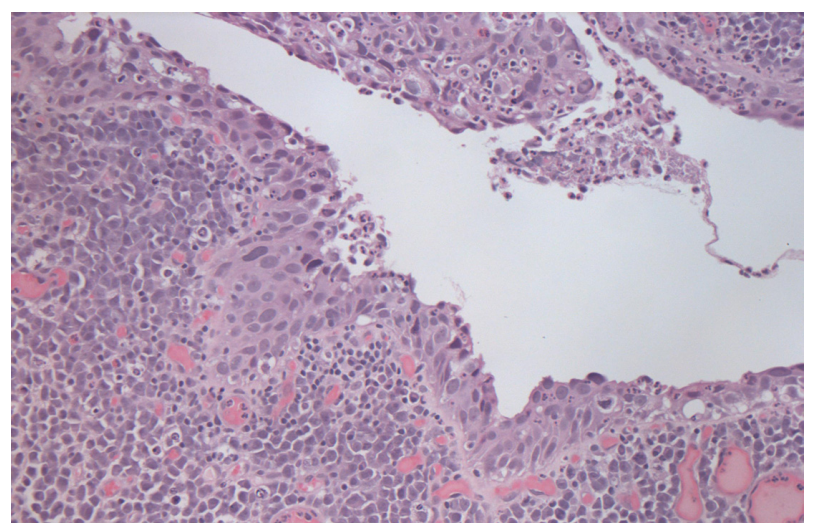

Figure I Demonstrates extensive carcinoma in situ of the urothelium. In the lamina propria there are a population of atypical cells with enlarged nuclei, prominent nucleoli and varying quantities of cytoplasm consistent with a plasma cell tumor.

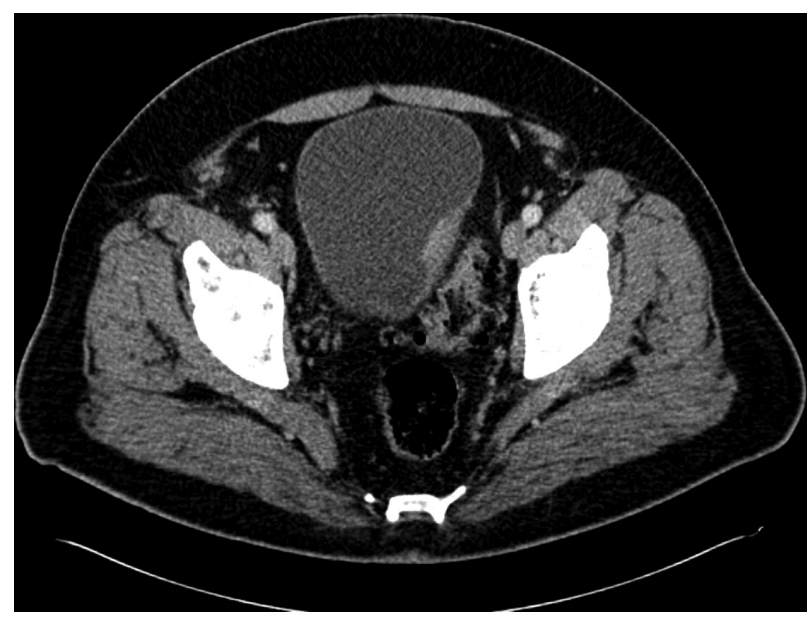

Figure 2 Demonstrates a localized mass in the posterior aspect of the bladder wall which is organ confined. There is no pelvic lymphadenopathy.

The diagnosis was therefore carcinoma in situ with an 'incidental' isolated extramedullary plasmacytoma of the urinary bladder.

As he had undergone a transurethral resection of bladder tumor, the patient was treated with adjuvant external beam radiotherapy with 45 Gy in 25 fractions. This treatment gained a good response with no recurrence of the carcinoma in-situ, and the plasmacytoma reduced in size.

\section{Discussion}

A plasmacytoma is discrete, proliferative mass of neoplastic monoclonal plasma cells which can be found in bone or soft tissue. Extramedullary plasmacytoma is commonly seen in the aerodigestive tract. ${ }^{1}$ The most common sites of occurrence are the paranasal sinuses, pharynx, nasal cavity gums, and oral mucosa. ${ }^{1,2-5}$ Cases have also been reported in the central nervous system, orbit, gastrointestinal system, liver, spleen, pancreas, lung, breast, skin, testis, parotid mediastinum, thyroid gland, and - although rarely - the urinary bladder. ${ }^{1,2-5}$ Only 21 cases of bladder extramedullary plasmacytoma (EMP) have been reported to date including one case in a renal transplant recipient. ${ }^{6}$ None have been reported with synchronous urothelial TCC. The relationship between transitional cell carcinoma and bladder EMP is not yet known.

Plasmacytoma of the urinary bladder is a rare extramedullary manifestation of plasma cell neoplasm. It is thought to arise from plasma cells in mucosal surfaces. ${ }^{7}$ The typical microscopic appearance is a sheet of discohesive cells with prominent nucleoli and eccentric eosinophilic cytoplasm ${ }^{8}$ but it has also been described as round cells with an eccentric 
cartwheel-like nucleus. ${ }^{9}$ It must be differentiated from plasmacytoid-type TCC which is a highly aggressive malignancy associated with a poor prognosis; this differentiation is sometimes difficult. ${ }^{9}$ The plasmacytoid-type TCC is an invasive epithelial malignancy. Histologically, it can be seen extending from the urothelium into the lamina propria, whereas plasmacytoma is noninvasive and is only found in the lamina propria.

EMPs are highly radiosensitive tumors and in the case of head/neck disease, survival at 10 years is in the order of $65 \% .{ }^{10}$ Treatments described for bladder EMP have included systemic chemotherapy, ${ }^{11}$ immunotherapy combined with chemotherapy, ${ }^{6}$ radium implants, ${ }^{12}$ cystectomy, ${ }^{9}$ and radiotherapy. ${ }^{13,14}$ Poorer outcomes are reported in those with systemic disease and $<10 \%$ of patients have local recurrence of the disease. ${ }^{6}$ Ten year disease-free and overall survival rates range from $50 \%-80 \%$, for the $30 \%-50 \%$ of patients who develop disease progression to myeloma. This occurs after a median of 1.5-2.5 years and their clinical course at progression is similar to those of patients diagnosed with de novo symptomatic myeloma. ${ }^{10}$ However, no specific longterm follow up data have been reported for bladder EMP.

\section{Conclusion}

EMP of the bladder is a very rare form of bladder cancer, with only 21 isolated case reports. This case represents the first report of synchronous bladder EMP and transitional cell carcinoma of the urothelium.

With a bladder mass seen on imaging but not on initial flexible cystoscopy, a high index of suspicion is required and biopsy/resection is necessary to eliminate EMP as a possible cause.

Given the radiosensitivity of EMP in other anatomical sites, the mainstay of treatment is currently radiotherapy (either adjuvant or radical) and prognosis appears to be better in those with no evidence of systemic disease.

\section{Disclosure}

The authors report no conflicts of interest in this work.

\section{References}

1. Wiltshaw E. The natural history of extramedullary plasmacytoma and its relation to solitary myeloma of bone and myelomatosis. Medicine. 1976;55(3):217-238.

2. Dimopoulos MA, Kiamouris C, Moulopoulos LA. Solitary plasmacytoma of bone and extramedullary plasmacytoma. Hematol Oncol Clin North Am. 1999;13(6):1249-1257.

3. Galieni P, Cavo M, Pulsoni A, et al. Clinical outcome of extramedullary plasmacytoma. Haematologica. 2000;85(1):47-51.

4. Alexiou C, Kau RJ, Dietzfelbinger H, et al. Extramedullary plasmacytoma: tumor occurrence and therapeutic concepts. Cancer. 1999;85(11):2305-2314.

5. Liebross RH, HaCS, Cox JD, etal. Clinical course of solitary extramedullary plasmacytoma. Radiother Oncol. 1999;52(3):245-249.

6. Takahashi R, Nakano S, Namura K, et al. Plasmacytoma of the urinary bladder in a renal transplant recipient. Int J Hematol. 2005;81(3): 255-257.

7. Chan TY, Epstein JI. In situ adenocarcinoma of the bladder. Am J Surg Pathol. 2001;25:892-899.

8. Murphy WM. Diseases of the urinary bladder, urethra, ureters, and renal pelves. In WM Murphy, ed. Urological pathology. Philadelphia, PA: Saunders, 1997:98-111

9. Lopez A, Mendez F, Puras-Baez A. Extramedullary plasmacytoma invading the bladder: case report and review of the literature. Urol Onc: Sem Orig Inv. 2003;21(6):419-423.

10. Tsang RW, Gospodarowiez MK, Pintille M, et al. Solitary plasmacytoma treated with radio therapy: Impact of tumor size on outcome. Int J Radiat Oncol Biol Phys. 2001;50:113-120.

11. Matsumiya K, Kanayama Y, Yamaguchi S, et al. Extramedullary plasmacytoma (EMP) of urinary bladder. Urology. 1992;40(1): 67-70.

12. GORFAIN AD. Extramedullary plasmacytoma of the bladder with local metastasis. Calif Med. 1949;71(2):147.

13. Mokhtar GA, Yazdi H, Mai KT. Cytopathology of extramedullary plasmacytoma of the bladder: a case report. Acta Cytolo. 2006;50(3): 339-343.

14. Shpilberg O, Raviv G, Ramon J, Goldwasser B, Ben-Bassat I, Ramot B. Massive haematuria due to extramedullary plasmacytoma invading the bladder. Med Pediatr Oncol. 1993;21(1):67-69.

\section{Publish your work in this journal}

The Open Access Journal of Urology is an international, peer-reviewed, open access journal publishing original research, reports, editorials, reviews and commentaries on all aspects of adult and pediatric urology in the clinic and laboratory including the following topics: Pathology, pathophysiology of urological disease; Investigation and treatment of

\section{Dovepress}

urological disease; Pharmacology of drugs used for the treatment of urological disease. The manuscript management system is completely online and includes a very quick and fair peer-review system, which is all easy to use. Visit http://www.dovepress.com/testimonials.php to read real quotes from published authors. 